\title{
Eröffnung der Tagung am 13. Oktober 1966
}

Nach der Eröffnung der Tagung im Festsaal der Karl-Franzens-Universität zu Graz begrüßte der Dekan der Rechts- und Staatswissenschaftlichen Fakultät, Prof. Dr. Karl Lechner, die Vereinigung im Namen des Rektors und der Fakultät. Er gab seiner Freude darüber Ausdruck, daß die Vereinigung, zum erstenmal in ihrer Geschichte, die traditionsreiche Stadt Graz zu ihrem Tagungsort gewählt habe. Der Vorsitzende, Herr Bachof, dankte der Universität und der Fakultät für ihre vielfachen Bemühungen um die Vorbereitung und Durchführung der Tagung. Er begrüßte den Präsidenten des Verfassungsgerichtshofs, Herrn Antoniolli, sowie die Mitglieder und Assistenten der gastgebenden Fakultät, die ausländischen Gäste und die Schriftleiter der Fachzeitschriften. Er übermittelte die Grüße des österreichischen Bundeskanzlers und des Kollegen Justizminister Klecatsky, der die Vereinigung am Vorabend namens der österreichischen Bundesregierung im Schloß Eggenberg empfangen hatte.

In der den Beratungen vorangegangenen Mitgliederversammlung hatte die Vereinigung ihres im letzten Jahre verstorbenen Mitgliedes und einstigen Vorsitzenden Hans Peters gedacht. Ihrem einstigen Mitgliede Hans Kelsen bekundete sie in einem Glückwunschtelegramm zu seinem 85. Geburtstag ihre Verbundenheit, wofür dieser mit herzlichen Worten gedankt hat. Die im vergangenen Jahr in die Vereinigung aufgenommenen Mitglieder wurden begrüßt und vorgestellt.

Die nachfolgend abgedruckten Referate wurden am 13. und 14. Oktober 1966 gehalten. An sie schlossen sich jeweils die Aussprachen an. 